\title{
Research on the impact of new energy automobile industry alliance development status on technological innovation
}

\author{
Zou Dewei ${ }^{1, *}$ \\ ${ }^{1}$ Beijing Jiaotong University, School of Economics and Management, Beijing, China
}

\begin{abstract}
With the increasing pressure on the ecological environment, the continuous progress of science and technology and the government's policy support for the new energy industry, the development momentum of China's new energy automobile industry is strong. However, the emerging industry still faces major obstacles in terms of technological innovation, standard-setting and marketization. In the face of these obstacles, industrial alliances, as an organizational form, have been widely used in the new energy vehicle industry in order to seek the risk sharing and cooperation effect of alliances. In this paper, on the basis of identifying the members of China's new energy automobile industry alliance and based on the classification theory of industrial alliance, China's new energy automobile industry alliance is divided into horizontal alliance and vertical alliance. In addition, this paper adopts the method of case study to put forward reasonable suggestions for the shortcomings existing in the development status of China's new energy vehicle industry alliance, so as to promote the technological innovation of the industry alliance.
\end{abstract}

\section{Introduction}

After the world financial crisis, the global traditional automobile industry suffered a heavy hit, and the new energy automobile industry gradually shows great development potential. In addition, the Chinese government has always given favorable policy support to the new energy automobile industry and attached importance to it as a national strategic industry, which makes China's new energy automobile industry after more than a decade of development, has achieved good results in the global new energy automobile industry. In the world, China's new energy vehicles rank the top in the market, but it is also worth noting that China's new energy vehicles lag behind in technology, especially with the United States and Japan.

As an organizational form of cooperation between enterprises, industrial alliance has been widely used in China's new energy vehicle industry to promote technological innovation, and has been strongly supported by the government. As a new technology, new energy vehicles are bound to have many technical difficulties to break through at the beginning stage. It is impossible for a car company to possess all the resources and capabilities required for technological innovation. This situation requires the alliance members to use the industrial alliance to carry out cooperative innovation, so as to form a greater synergy and influence in the field of new energy vehicles in China, and further promote China's automobile industry, to achieve the "overtaking at the corner" in the field of international automobile industry.

Therefore, by analyzing the advantages and disadvantages of China's new energy vehicle industry alliance, it is of certain practical significance to provide reasonable suggestions for promoting China's new energy vehicle industry alliance's technological innovation.

\section{Development status of new energy vehicle industry alliance}

\subsection{Classification theory of industrial alliance}

On the classification of industrial alliance, domestic and foreign scholars put forward different classification methods. This paper draws on the classification method of American scholars Peng S. Han and Dorothy E. Heide.

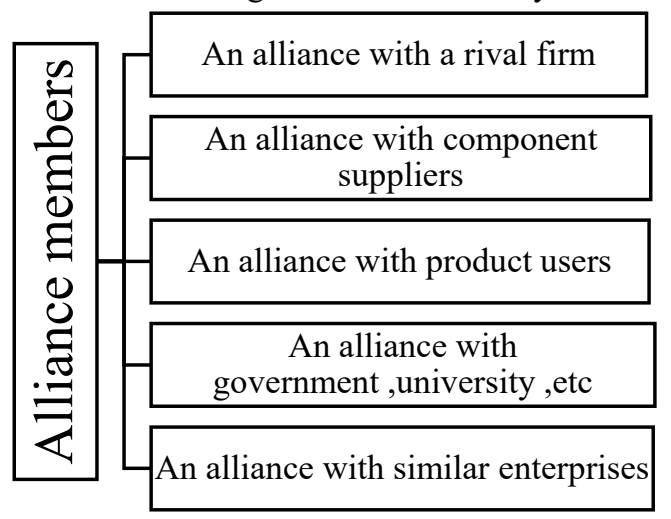

Fig. 1. Classification of industrial alliances

This classification method has important reference significance for the new energy vehicle industry alliance to be discussed in this paper. Because these five types of industrial alliances are very similar to the members of the

\footnotetext{
* Corresponding author: zoudewei98@163.com
} 
new energy vehicle industry alliance to be discussed in this paper -- government, industry, university, institute and user.

In addition, the five alliance modes in the figure can be combined, which leads to the two alliance modes discussed in this paper: horizontal alliance (alliance formed with competitor enterprises) and vertical alliance (integration of the above five alliances).

\subsection{China's new energy vehicle industry alliance}

Within the scope of China's new energy vehicle industry, the organizational form of industrial alliance has been widely used at all levels. Numerous new energy vehicle industry alliances have been established at the national, local, industrial and international levels.

At present, the main members of China's new energy vehicle industry alliance include five major parts: government, enterprises, universities, research institutions and users. In addition, the enterprise side members can be subdivided into $\mathrm{R} \& \mathrm{D}$ enterprises and service enterprises.Among them, R \& D enterprises are mainly responsible for the research and development of raw materials, parts, infrastructure and vehicles, while service enterprises are mainly responsible for the operation, sales, maintenance, finance and other follow-up services.

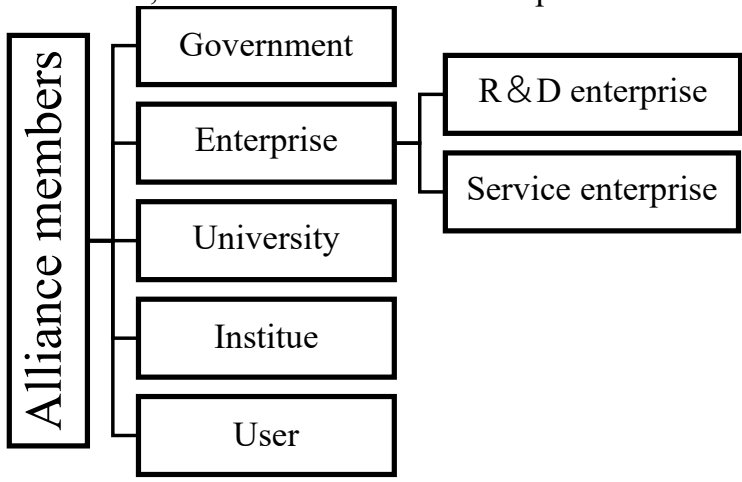

Fig. 2. Member of New Energy Vehicl6e Industry Alliance

The different combinations of these five organizations constitute the various forms of industrial alliances in China. According to the upstream and downstream relationship of different institutions in the market, this paper specifically introduces the horizontal and vertical forms of new energy vehicle industry alliance.

\subsubsection{Horizontal Alliance Model}

The alliance formed by enterprises carrying out similar activities in the same industry is called horizontal alliance, whose purpose is to carry out technical cooperation and resource sharing.

Among the many cases of China's new energy vehicle horizontal industry alliance, this paper takes TOP10 electric vehicle industry alliance as the typical case as the research object.Led by the China Association of Automobile Manufacturers (CAAM), the Alliance is an alliance of 10 major Chinese automobile conglomerates whose main task is to set standards for the new energy vehicle industry.
In the horizontal alliance, the strength and ability of each enterprise are roughly the same, and the goal of technological breakthrough is basically the same. Compared with the cooperation with universities and scientific research institutions, the cooperation is much smoother. After the formation of horizontal alliance, new energy vehicle enterprises can complement each other in resources to make joint innovation through their respective advantages and improve the probability of successful research and development.

In horizontal alliance, the relationship between competition and cooperation must be properly handled because the alliance enterprises are in a state of competition in the same industry. Once the relationship between competition and cooperation is not handled well, the whole alliance will collapse.

\subsubsection{Vertical Alliance Model}

The alliance established by different enterprises with complementary resource advantages is called vertical alliance.In the field of China's new energy vehicle industry alliance, this mode is more widely adopted than the horizontal alliance mode.

Beijing New Energy Vehicle Industry Alliance was established on March 13, 2009, becoming the first new energy vehicle industry alliance in China. This alliance is a typical vertical alliance model.

In the vertical alliance model, universities, research institutions and component suppliers are in the upstream, vehicle manufacturers are in the middle, and users are in the downstream. The main characteristic of vertical alliance is that different subjects have a high degree of dependence and complementarity. Vertical alliance integrates the advantages of different subjects in the whole industrial chain, thus making up for their own shortcomings and improving the innovation ability of the whole alliance.

Different from horizontal alliances, vertical alliances are located at different locations in the industrial chain, so there are big problems in the distribution of benefits. The main problem facing vertical alliances is how to develop the indicators to measure the contributions of each institution so as to reasonably distribute benefits.

\section{Case study}

In this paper, a typical case of horizontal alliance -- Top10 Electric Vehicle Industry Alliance and a typical case of vertical alliance -- Beijing New Energy Vehicle Industry Alliance are selected as the case study objects to reveal the common problems of China's current new energy vehicle industry alliance.

\subsection{Horizontal Alliance Case -- Top10 Electric Vehicle Industry Alliance}

Top10 Electric Vehicle Industry Alliance (hereinafter referred to as T10) was formally established in China Automotive Industry T10 Summit held in July 2009 under the leadership of China Association of Automobile 
Manufacturers. The alliance was a typical horizontal alliance model, which was composed of FAW, SAIC, Changan, Dongfeng, BAIC, GAC, Sinotruk, Chery, Brilliance and Jianghuai, which were among the top ten vehicle enterprise groups in terms of sales at that time.

T10 integrates the national advanced vehicle technology resources, and establishes the overall strategy of "active guidance, joint action, focus, innovation and development".

T10 members are all powerful vehicle enterprises.Although members have their own characteristics and advantages in the development of the new energy automobile industry, enterprises have different priorities in strategic goals and R\&D investment, but they all face common problems in the healthy development of the new energy automobile industry. For example, the breakthrough of battery, motor and electronic control technology, the formulation of new energy vehicle standards and the better realization of new energy vehicles' marketization all need the cooperation of alliance members.

T10 not only implemented the "Common Platform for Action for Development", but also set up a standards working group, which is responsible for jointly formulating various standards for new energy vehicles. At the same time, in terms of technological innovation, T10 proposes two ways to promote cooperative innovation among members: one is the way of sharing outstanding achievements and joint development among members of the alliance, and the other is the way of solving technical problems jointly by members.

The relationship between competition and cooperation is very important to the horizontal alliance, which will lead to the collapse of the whole alliance if it is not handled properly.The handling of $\mathrm{T} 10$ in competition and cooperation relationship is of great reference significance, and the key to its success lies in:

(1) Alliance enterprises have different product lines

For automobile enterprise located in the industrial chain of the same link, the competition relationship must exist. However, each enterprise product line is not exactly the same.As a result, the products of the whole alliance cover the fields of passenger cars and commercial vehicles. For example, the product lines of SAIC and Chery are dominated by passenger cars, while those of Dongfeng and Jianghuai are dominated by trucks. As a result, the competitive relationship among the enterprises in the alliance is greatly weakened, and vicious competition will not lead to the failure of the alliance.

(2) Coordinating role of China Association of Automobile Manufacturers

As T10 enterprises are comparable vehicle enterprises, no one enterprise has absolute advantage.As a result, buck-passing is bound to occur, resulting in higher costs of communication and coordination. However, under the leadership of China Association of Automobile Manufacturers (CAAM), which is responsible for managing and coordinating matters in the alliance, the coordination and cooperation of T10 went smoothly after its establishment and improved the operational efficiency of the whole alliance.

\subsection{Vertical Alliance Case -- Beijing New Energy Automobile Industry Alliance}

On March 13, 2009, the establishment of Beijing New Energy Automobile Industry Alliance means that China's first new energy automobile industry alliance was formally established, and since then China's new energy automobile industry alliance has entered the vigorous development stage.

Through specific analysis of the members, the Beijing New Energy Automobile Industry Alliance includes a government and related institutions, $24 \mathrm{R} \& \mathrm{D}$ companies, 2 service-oriented companies, 5 universities, 3 research institutions, and 30 user units. In addition, the alliance gathers stakeholders in various fields in the process of industry development, including international excellent resources integrated in the form of joint ventures and cooperation.

From the members of the alliance, it can be seen that the advantageous resources of domestic and foreign new energy vehicle industry are integrated into the alliance. The alliance is a typical vertical alliance model, with members from all links of the industrial chain -- parts suppliers, research institutions, vehicle manufacturers and users. The alliance seeks to achieve win-win cooperation in information communication, technological innovation, policy advocacy and standard-setting.

However, due to the inherent shortcomings of vertical alliances, the members of Beijing New Energy Automobile Industry Alliance are located in different links of the industrial chain, which is bound to increase the difficulty of management and coordination. At the same time, the contribution of members in different links of the industrial chain to the alliance is difficult to be determined by quantitative standards, so it is difficult to reach a unanimous decision on benefit distribution, which increases the difficulty of interest coordination. At the same time, there are many foreign enterprises among the members of the alliance, which also brings great challenges to cross-cultural management.

Through the case study of Beijing New Energy Automobile Industry Alliance, the successful experience can be summarized as follows:

(1) Beijing New Energy Automobile Industry Association (hereinafter referred to as the "Association") was founded.

The association is the first one in China that takes the coordinated development of the whole industry chain of new energy vehicles as its goal. It has played a very good supervisory and management role in Beijing New Energy Automobile Industry Alliance, making it more professional and standardized.

The association has made important contributions to the establishment of technical standards, the promotion of technical innovation and the expansion of brand influence of the alliance. At the same time, the association has better coordinated the relationship between parts supply, research and development, manufacturing, users and other aspects of the industry chain, and held a series of activities such as enterprise external exchanges, user consulting services, automobile industry exhibitions, etc., which has greatly enhanced the industrial capacity of the alliance and 
promoted the technical progress of the alliance.

(2) The establishment of Beijing New Energy Vehicle Industry Alliance Expert Committee.

Beijing New Energy Vehicle Industry Association has specially set up an expert committee to provide technical support for different technology innovation modules of new energy vehicles. The committee is composed of seven modules, which can promote the technological innovation of different modules in a more targeted way, which greatly speeds up the breakthrough speed of the technical difficulties of each module of new energy vehicles.

\section{Countermeasures and suggestions for promoting technological innovation of new energy automobile industry alliance}

Based on the study of the development status and typical cases of China's new energy vehicle industry alliance, the following factors affecting the technological innovation of new energy vehicle industry alliance are summarized.

First of all, the rights and responsibilities of the cooperative members of the alliance are not clear, and the actual cooperation effect is not good; Secondly, China's new energy vehicle industry alliances are scattered, and there is a lack of unified goals, standards and management; In addition, the members of the industrial alliance have conflicts in the allocation of funds; Finally, most of China's industrial alliances lack members engaged in infrastructure construction.

In view of the above problems, this paper puts forward the following suggestions to promote the technological innovation of the new energy vehicle industry alliance.

\subsection{The Alliance Management Agency shall be established to be responsible for the efficient operation of the Alliance}

Through the analysis of the above two cases, the common experience obtained from them -- the supporting role of the alliance management organization. No matter in a vertical alliance or a horizontal alliance, the cooperation among members cannot always be carried out smoothly, and the cooperation effect is not good in the actual operation process, and many positive plans have not been implemented. In view of this problem, the establishment of a coordinated alliance management organization can play a role of communication and coordination, act as the "lubricant" among alliance members, promote the healthy and sustainable development of the alliance, improve the joint force and influence of the industrial alliance, and better promote the technological innovation ability of the industrial alliance.

\subsection{Clarifying the criteria of the Alliance}

Due to the limitations of a single enterprise itself, its strength is not enough to control the market, separate development of various standards. Therefore, enterprises can cooperate on the basis of common interests, establish a standard committee of industrial alliance, and jointly participate in the formulation of standards of new energy automobile industry alliance. In this way, on the one hand, the capital cost invested by enterprises in independent research and development is reduced, and on the other hand, the time required for technological innovation is greatly shortened.

The standards of the alliance include not only unified standards on the technical level, such as parts and vehicle manufacturing, but also standards on the management level, such as performance assessment and intellectual property protection. First of all, the members of the alliance can clearly define the rights and responsibilities of each member by signing agreements and articles to ensure the consistency of rights and responsibilities. Secondly, cooperate with other alliances to determine the technical standards for the development of the new energy vehicle industry, which will facilitate the development of the entire industry rather than the development of a single industrial alliance. In addition, the respective performance standards of the alliance members should be clearly stipulated, and scientific quantitative standards should be formulated for different subjects, so as to provide a clear basis for profit distribution and achieve fairness and rationality.

\subsection{Protect the intellectual property rights of members of the Alliance}

Since the main goal of industrial alliance is to achieve technological breakthrough, the alliance must attach great importance to the protection of intellectual property rights. Especially in vertical alliances, universities and research institutions are mainly responsible for research and development and technological breakthroughs in the industrial chain. However, due to the existence of "leading" vehicle enterprises in the whole industrial chain, universities, scientific research institutions and parts suppliers and other members are easily subjected to unfair treatment, resulting in research and development results can not be reasonably protected, the ownership of the results can not be properly handled, thus bringing difficulties to the distribution of interests.

At this time, the government or the alliance management agency should play a regulatory role, seriously study the ownership of intellectual property rights, and make a profit distribution plan according to the pre-determined standards to ensure that the interests of the alliance members will not be damaged and the enthusiasm of the alliance members for technological innovation will be protected.

\subsection{Reasonable selection of cooperative members of the industrial alliance}

No matter what kind of alliance or team you build, you must first choose the right members. At the beginning of the establishment of the new energy vehicle industry alliance, each enterprise must combine its own advantages and characteristics to reasonably choose the alliance partners that are complementary. First of all, it is necessary 
to consider whether the alliance members have the same strategic goals and development direction in the field of new energy vehicles, and whether they can complement and help each other in terms of resources and capabilities. Secondly, it is necessary to analyze the company status of the candidate members, such as the company's business performance, financial status, research and development capabilities, etc., so as to realize the strong alliance and avoid the development of the alliance hindered by improper selection.

Specifically, through the case study, it is pointed out that for horizontal alliance, in order to avoid excessive competition of similar enterprises, special attention should be paid to whether there is overlap of product lines between members in the selection of alliance, and members with different product lines should be selected as far as possible for cooperation, so as to avoid fierce competition within the alliance members. For vertical alliance, it is mainly concerned about whether members in different links of product chain can complement each other in resource advantages, so as to promote the improvement and development of the whole industrial chain.

Here, it is also worth noting that cooperation with the government and infrastructure units should be emphasized. Only by improving the infrastructure needed by new energy vehicles can new energy vehicles be better accepted by consumers and better achieve marketization.

\section{References}

1. Liang Fenghui. Research on the Model of Industryuniversity-research Alliance of Jilin Province New Energy Vehicle Industry [D]. Changchun University of Technology,2012.

2. Jin Fei. Research on the Development of China's New Energy Automobile Industry Alliance [D]. Huazhong University of Science and Technology,2011.

3. Wang Jingyu.(2016) Research on the Development Status and Technological Innovation Mode of China New Energy Vehicle Industry Alliance.J.Science and Technology Management Research,36(22):162-171.

4. WANG Jingyu. Research on Technology Innovation of China New Energy Vehicle Industry Alliance [D]. Beijing Jiaotong University,2017.

5. Liu Jie, Zhang Shuifeng.(2008)The establishment of alliance standard is the core link of enterprises competing for the right to speak of standard.J. China Standard Review,(02):18-20.

6. Liu Yingqi. (2011)The Impact of Firm-University Relationship on Technological Innovation in New Energy Vehicle Industry Alliance.J.Management World,(06):182-183.

7. Liu Yingqi, Gao Hongwei.(2011)Technological innovation development trend and countermeasures of China new energy vehicle industry alliance.J. Scientific Decision,(02):1-8.

8. Zhang Yanfei.(2015)A multi-case study on collaborative innovation mechanism of emerging technology industry alliance.J. Shandong Social Sciences, (06):110-116.

9. Li Jian, Han Ziyan, Liu Lankai.(2015)Theoretical analysis of industrial alliance standards and their effectiveness.J. Exploration of Economic Problems, (06):60-66. 